\title{
Pengaruh Sosialisasi Kebijakan Merdeka Belajar Kampus Merdeka (MBKM) terhadap Keberhasilan Pelaksanaan MBKM di Universitas 17 Agustus 1945 Jakarta
}

The Socialization Effect of the Freedom to Learn-Independent Campus on the MBKM Successful Implementation at the University of 17 August 1945 Jakarta

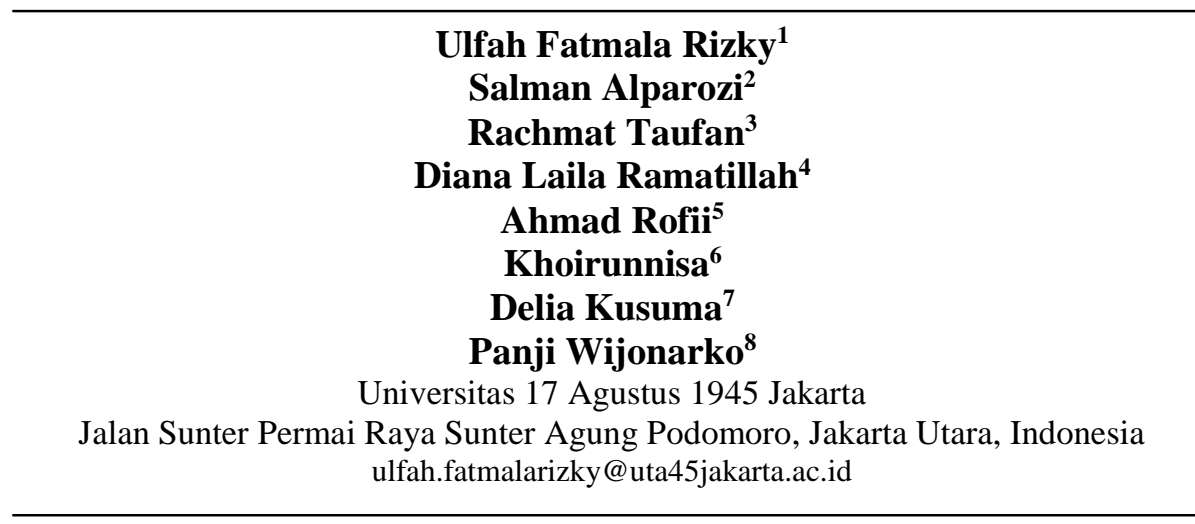

Dikirim: 27 Desember 2021, Direvisi: 31 Desember 2021, Diterima: 31

Desember 2021, Terbit: 31 Desember 2021. Sitasi: Rizky dkk,. (2021).

Pengaruh Sosialisasi Kebijakan Merdeka Belajar Kampus Merdeka (MBKM) terhadap Keberhasilan Pelaksanaan MBKM di Universitas 17 Agustus 1945

Jakarta , PRoMEDIA. Volume 7 (2), Desember 2021, hal 413- hal 430.

\begin{abstract}
In 2020, the Ministry of Education, Culture, Research, and Technology (Kemendikbudristek) of the Republic of Indonesia (R.I) launched the Freedom to Learn-Independent Campus (MBKM) policy. To implement this policy, the University of 17 August 1945 Jakarta (UTA '45 Jakarta) has made adjustments to its internal policies in academic development, curriculum, and all resources, including intensive socialization. However, out of 1103 lecturers and students of UTA '45 Jakarta, only 252 people became participants in the MBKM program. For this reason, this study aims to determine whether the socialization of the MBKM policy conducted at UTA '45 Jakarta affected the successful
\end{abstract}


implementation of MBKM programs at UTA ' 45 Jakarta. This study is the first study to discuss the effect of the socialization of MBKM policies on the success of MBKM implementation. The method used is a quantitative method. The results showed that the socialization of MBKM policy at UTA '45 Jakarta influenced the success of MBKM implementation at UTA' 45 Jakarta.

Keywords: Socialization, policy implementation, $M B K M$

\section{Abstraksi}

Pada tahun 2020, Kementerian Pendidikan, Kebudayaan, Riset, dan Teknologi (Kemendikbudristek) Republik Indonesia (R.I) meluncurkan kebijakan Merdeka Belajar Kampus Merdeka (MBKM). Untuk dapat mengimplementasikan kebijakan tersebut, Universitas 17 Agustus 1945 Jakarta (UTA '45 Jakarta) telah melakukan penyesuaian kebijakan internal dalam pengembangan akademik, kurikulum, dan segala sumber daya, termasuk melakukan sosialisasi secara intensif. Namun demikian, dari 1103 jumlah dosen dan mahasiswa UTA ' 45 Jakarta hanya 252 orang yang menjadi peserta program MBKM. Untuk itu, penelitian ini bertujuan untuk mengetahui apakah sosialisasi kebijakan MBKM yang dilakukan di UTA '45 Jakarta berpengaruh terhadap keberhasilan pelaksanaan program-program MBKM di UTA ' 45 Jakarta. Penelitian ini merupakan penelitian pertama yang membahas tentang pengaruh sosialisasi kebijakan MBKM terhadap keberhasilan pelaksanaan MBKM. Metode yang digunakan adalah metode kuantitatif. Hasil penelitian menunjukkan bahwa sosialisasi kebijakan MBKM di UTA '45 Jakarta mempengaruhi keberhasilan implementasi MBKM di UTA '45 Jakarta.

\section{Kata Kunci: sosialisasi, implementasi kebijakan, MBKM}

\section{PENDAHULUAN}

Kebijakan Merdeka Belajar Kampus Merdeka (MBKM) diluncurkan oleh Kementerian Pendidikan, Budaya, Riset, dan Teknologi (Kemendikbudristek) pada tahun 2020. Direktorat 
Jenderal Pendidikan Tinggi (2020) menyampaikan bahwa implementasi kebijakan MBKM menjamin kesempatan mahasiswa untuk bisa belajar di luar program studi selama tiga semester, yang bertujuan untuk meningkatkan kompetensi soft skill dan hard skill lulusan atau mahasiswa aktif sehingga siap untuk menghadapi dunia kerja.

Kebijakan Merdeka Belajar Kampus Merdeka bertujuan untuk meningkatkan kompetensi soft skills dan hard skills mahasiswa sehingga lebih siap dan relevan dengan kemajuan zaman. Program-program MBKM juga diharapkan dapat memberikan kesempatan kepada mahasiswa untuk mengembangkan potensinya sesuai dengan minat dan bakatnya. Pentingnya manfaat program-program MBKM mendorong Universitas 17 Agustus 1945 Jakarta berkomitmen untuk melaksanakan program-program MBKM, baik yang diselenggarakan oleh Kemendikbudristek ataupun programprogram MBKM yang dilaksanakan mandiri oleh perguruan tinggi.

Program MBKM dapat dibedakan menjadi dua, yaitu: program MBKM yang diselenggarakan oleh Kemendikbudristek dan program MBKM internal perguruan tinggi. Universitas 17 Agustus 1945 Jakarta merupakan salah satu perguruan tinggi yang melaksankana program MBKM Kemendikbudristek dan MBKM internal. Program MBKM Kemendikbudristek, yaitu: Pertama, Program Pertukaran Mahasiswa Merdeka Dalam Negeri. Kedua, 
Program Kampus Mengajar. Ketiga, Program Magang dan Studi Independen Bersertifikat. Keempat, Program KKN Tematik. Kelima, Proyek Kemanusiaan, Keenam, Program Riset atau Penelitian. Ketujuh, Kegiatan Wirausaha, Program Transfer Kredit Internasional. Kedelapan, Program Indonesia International Student Mobility Awards. Adapun kegiatan MBKM internal di antaranya adalah program pertukaran mahasiswa di Unversiti Sains Malaysia, yang bernama USM Online Exchange Program.

Salah satu variabel pendorong keberhasilan implementasi kebijakan adalah komunikasi yang efektif. Indikator ini disampaikan oleh van Metter, van Horn, dan George C. Edward III (Agustino, 2016). Edward dalam (Agustino, 2016) menyebutkan tiga indikator komunikasi yang berpengaruh terhadap efektivitas implementasi kebijakan, yaitu: pertama, transmisi atau penyaluran komunikasi. Kedua, komunikasi yang diterima oleh para pelaksana kebijakan harus jelas dan tidak ambigu. Ketiga, konsistensi perintah yang diberikan untuk diterapkan sangat penting untuk menghindari kebingungan pada pelaksana kebijakan di lapangan. Komunikasi dan koordinasi yang terjalin dengan baik di antara para pihak yang terlibat dalam proses implementasi kebijakan dapat mengurangi risiko terjadinya kesalahan atau permasalahan yang tidak diinginkan Agustino (2016). Untuk dapat membangun komunikasi yang efektif diperlukan saluran-saluran komunikasi yang baik sehingga perintah atau isi dari kebijakan dapat diteruskan dengan benar (Syarif, Unde, \& Asrul, 2014). 
Terdapat sejumlah model komunikasi yang dapat digunakan untuk memahami proses komunikasi. Salah satu model komunikasi tersebut adalah model komunikasi yang ditemukan oleh Harold Laswell, di mana komunikasi terdiri dari lima unsur, yaitu: komunikator, pesan, saluran komunikasi, komunikan, dan pengaruh..

Gambar 1. Model Komunikasi Harold Laswell

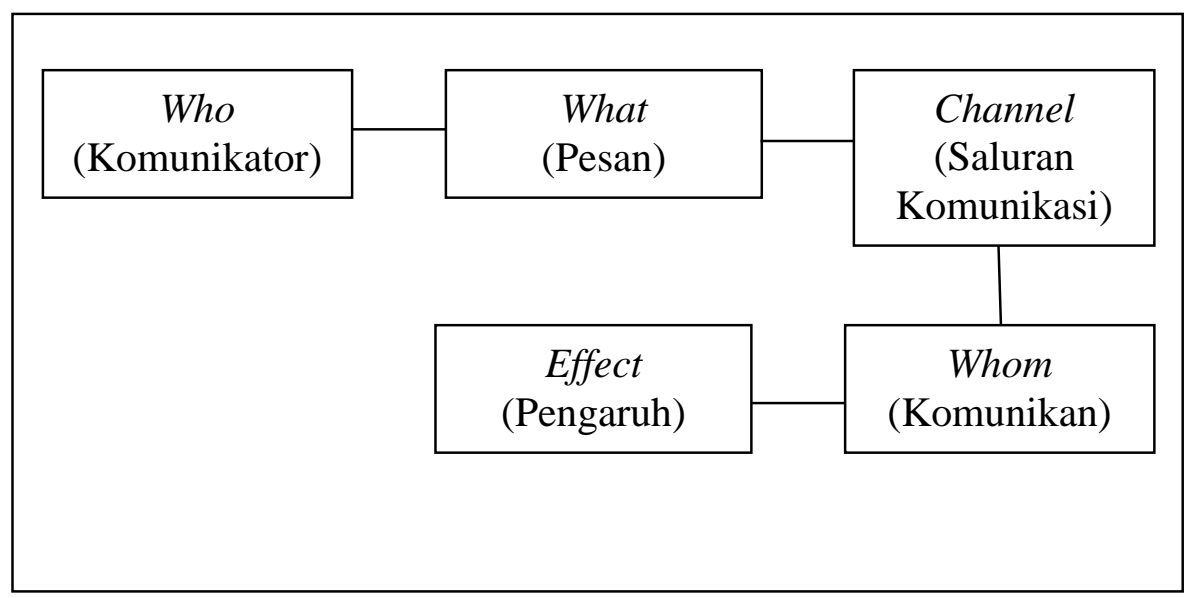

Sumber: Rustan \& Hakki (2017, hal. 100)

Terdapat tiga bentuk saluran komunikasi, yaitu: pertama, komunikasi antar pribadi yang terjalin antara dua pihak, langsung, dan dalam bentuk percakapan lisan atau tulisan. Kedua, komunikasi antar kelompok yang berlaku antara seorang komunikator dengan sejumlah komunikan (kelompok kecil atau kelompok besar) yang berkumpul bersama. Ketiga, komunikasi massa, yaitu komunikasi yang menggunakan media dalam menghubungkan komunikator dengan komunikan secara massal, 
berjumlah banyak, heterogen, bertempat tinggal jauh, dan menibulkan efek-efek tertentu (Thomas, 2018).

Universitas 17 Agustus 1945 Jakarta (UTA '45 Jakarta) merupakan salah satu perguruan tinggi swasta yang terlibat aktif dalam implementasi kebijakan MBKM. Salah satu bentuk saluran komunikasi yang digunakan oleh UTA '45 Jakarta untuk menyebarkan informasi di kalangan civitas akademika UTA ' 45 Jakarta adalah sosilaisasi daring dengna menggunakna apliaksi konferensi video Zoom. Pelaksanaan MBKM di UTA '45 Jakarta diawali dengan sosialisasi tentang kebijakan, persyaratan, dan prosedur pendaftaran program-program MBKM, baik program MBKM dari Kemendikbudristek ataupun program MBKM internal UTA '45 Jakarta. Namun demikian, seperti yang disajikan pada tabel 1, hanya 252 dosen dan mahasiswa UTA ' 45 Jakarta yang berpartisipasi dalam program-program MBKM. Jumlah ini tentu sangat sedikit jika dibandingkan dengan jumlah total dosen dan mahasiswa di UTA '45 Jakarta yang mencapai 1.103 orang.

Tabel 1. Data Jumlah Peserta Program-Program MBKM

\begin{tabular}{|c|c|c|}
\hline No. & Nama Program & Jumlah Peserta \\
\hline 1. & $\begin{array}{l}\text { Pertukaran Mahasiswa } \\
\text { Merdeka Dalam Negeri }\end{array}$ & $\begin{array}{l}\text { - } \text { Mahasiswa Outbound: } \\
14 \text { orang } \\
\text { - } \text { Mentor Modul } \\
\text { Nusantara: 1 orang } \\
\text { - } \\
\text { Dosen Nusantara: 1 orang } \\
\text { - } \\
\text { Dosen Matakuliah: } 4 \\
\text { orang }\end{array}$ \\
\hline 2. & Kampus Mengajar & 2 orang \\
\hline
\end{tabular}


PROMEDIA (PUBLIC RELATION DAN MEDIA KOMUNIKASI) ISSN 2460-9633

Volume Ke-7 No. 2, 2021, Rizky, dkk, Pengaruh Sosialisasi MBKM, hal 413- hal 430

\begin{tabular}{|l|l|l|}
\hline 3. & $\begin{array}{l}\text { Magang Bersertifikat } \\
\text { Kampus Merdeka }\end{array}$ & 4 orang \\
\hline 4. & $\begin{array}{l}\text { Studi Independen } \\
\text { Bersertifikat Kampus } \\
\text { Merdeka }\end{array}$ & orang \\
\hline 5. & $\begin{array}{l}\text { Kredensial M Mikro } \\
\text { Mahasiswa Indonesia }\end{array}$ & 200 orang \\
\hline 6. & World Class Professor & 1 orang \\
\hline 7. & $\begin{array}{l}\text { Transfer Kredit } \\
\text { Internasional di Dubai } \\
\text { Pharmacy College }\end{array}$ & $\begin{array}{l}\text { Universiti Sains Malaysia } \\
\text { USM) Online Exchange } \\
\text { Program }\end{array}$ \\
\hline 8. & 252 orang \\
\hline
\end{tabular}

Sumber: Hasil Penelitian (2021)

Terdapat sejumlah penelitian terdahulu yang mempelajari implementasi program MBKM, anatara lain: pertama, penelitian (Fuadi \& Aswita, 2021) yang menemukan bahwa terdapat lima tantangan yang dihadapi oleh perguruan tinggi swasta dalam melaksanakan program MBKM, yaitu: proses adaptasi kurikulum, terbatasnya kampus mitra, terbatasnya kolaborasi perguruan tinggi swasta di Aceh dengan mitra, tidak adanya anggaran yayasan perguruan tinggi untuk program MBKM, dan kualitas serta produktivitas SDM dosen dan mahasiswa. Kedua, penelitian Puspitasari \& Nugroho (2021) yang menemukan sejumlah faktor penyebab tidak efektifnya implementasi kebijakan MBKM di FISIP UPN Veteran Jawa Timur, antara lain: sistem perguruan tinggi yang belum siap, sulitnya nengkonversikan mata kuliah, proses kerja sama yang rumit, masalah SDM, kurangnya dukungan 
dari mahasiswa, dan adanya penetapan kuota. Ketiga, studi Baharuddin (2021) yang mendeskripsikan tentang adaptasi kurikulum Merdeka Belajar Kampus Merdeka. Berdasarkan penelitian terdahulu tersebut, belum ada penelitian yang membahas tentang pengaruh sosialisasi kebijakan MBKM terhadap keberhasilan pelaksanaan MBKM. Untuk itu, penelitian ini bertujuan untuk mengetahui apakah sosialisasi kebijakan MBKM yang dilakukan secara daring di UTA '45 Jakarta berpengaruh terhadap keberhasilan pelaksanaan program-program MBKM di UTA ‘45 Jakarta.

\section{METODOLOGI PENELITIAN}

\section{A. Jenis Penelitian}

Penelitian ini menggunakan metode kuantitatif, yaitu penelitian yang digunakan untuk meneliti populasi tertentu, proses dalam pengumpulan data penelitian ini menggunakan kuesioner daring dengan menggunkan aplikasi Google Form, analisis data yang digunakan bersifat kuantitatif/statistik yang bertujuan untuk mendapatkan hasil yang maksimal. Responden penelitian ini adalah mahasiswa Universitas 17 Agustus 1945 Jakarta.

\section{B. Teknik Pengumpulan Data}

Jenis data yang digunakan untuk penelitian ini adalah data primer dan data sekunder. Data primer didapatkan dari 
data kuesioner yang telah diisi oleh responden, sedangkan data sekunder berasal dan sumber pustaka, yang meliputi buku dan artikel jurnal. Data dikumpulkan dari 1012 mahasiswa UTA '45 Jakarta

\section{Teknik Analisis Data}

Untuk dapat mengetahui pengaruh dari kebijakan MBKM (independen) terhadap keberhasilan MBKM (dependen), maka dilakukan pengolahan data dengan menggunakan program IBM SPSS 25. Hasil pengolahan data sudah melalui beberapa tahapan yang meliputi pengujian validitas, pengujian reabilitas, dan pengujian hipotesis.

\section{PEMBAHASAN}

\section{A. Responden}

Tabel 2. Responden Penelitian

\begin{tabular}{|c|c|c|c|}
\hline \multicolumn{2}{|c|}{$\begin{array}{l}\text { Pengelompokan Berdasarkan } \\
\text { Fakultas }\end{array}$} & $\begin{array}{c}\text { Frequenc } \\
y\end{array}$ & Percent \\
\hline \multirow{6}{*}{ Valid } & $\begin{array}{l}\text { Fakultas Ilmu Sosial \& } \\
\text { Politik }\end{array}$ & 192 & $19 \%$ \\
\hline & Fakultas Hukum & 81 & $8 \%$ \\
\hline & Fakultas Teknik & 97 & $9.60 \%$ \\
\hline & Fakultas Farmasi & 450 & $44.50 \%$ \\
\hline & $\begin{array}{l}\text { Fakultas Ekonomi dan } \\
\text { Bisnis }\end{array}$ & 192 & $19 \%$ \\
\hline & Total & 1012 & $100 \%$ \\
\hline
\end{tabular}

Sumber : Data diolah IBM SPSS 25 


\section{B. Uji Validitas}

Tabel 3. Uji Validitas Sosialisasi Kebijakan MBKM di UTA '45 Jakarta

\begin{tabular}{c|c|c|c}
\hline & $\begin{array}{c}\text { Corrected Item- } \\
\text { Total Correlation }\end{array}$ & T Tabel & Keterangan \\
\hline XP1 & 0.588 & 0.062 & Valid \\
\hline XP2 & 0.624 & 0.062 & Valid \\
\hline XP3 & 0.713 & 0.062 & Valid \\
\hline XP4 & 0.723 & 0.062 & Valid \\
\hline XP5 & 0.762 & 0.062 & Valid \\
\hline XP6 & 0.71 & 0.062 & Valid \\
\hline XP7 & 0.71 & 0.062 & Valid \\
\hline XP8 & 0.685 & 0.062 & Valid \\
\hline XP9 & 0.704 & 0.062 & Valid \\
\hline XP10 & 0.676 & 0.062 & Valid \\
\hline XP11 & 0.755 & 0.062 & Valid \\
\hline XP12 & 0.772 & 0.062 & Valid \\
\hline XP13 & 0.753 & 0.062 & Valid \\
\hline XP14 & 0.514 & 0.062 & Valid \\
\hline XP15 & 0.707 & 0.062 & Valid \\
\hline XP16 & 0.629 & 0.062 & Valid \\
\hline XP17 & 0.708 & 0.062 & Valid \\
\hline XP18 & 0.686 & 0.062 & Valid \\
\hline XP19 & 0.727 & 0.062 & Valid \\
\hline XP20 & 0.696 & 0.062 & Valid \\
\hline
\end{tabular}

Sumber: data diolah IBM SPSS Ststisctic 25

Data pada tabel 3 menjelaskan bahwa hasil dari uji validitas Sosialisasi Kebijakan MBKM menunjukan bahwa $r$ hitung $\geq r$ tabel 
dengan nilai 0.062. Hal ini dapat dijelaskan bahwa semua pernyataan-pernyataan yang diberikan dalam bentuk kuisioner kepada seluruh mahasiswa UTA 45 Jakarta dapat dikatakan valid.

Tabel 4. Uji Validitas Keberhasilan Pelaksanaan MBKM di UTA '45 Jakarta

\begin{tabular}{c|c|c|c}
\hline & $\begin{array}{c}\text { Corrected Item- } \\
\text { Total Correlation }\end{array}$ & T Tabel & Keterangan \\
\hline YP1 & 0.568 & 0.062 & Valid \\
\hline YP2 & 0.593 & 0.062 & Valid \\
\hline YP3 & 0.707 & 0.062 & Valid \\
\hline YP4 & 0.726 & 0.062 & Valid \\
\hline YP5 & 0.73 & 0.062 & Valid \\
\hline YP6 & 0.688 & 0.062 & Valid \\
\hline YP7 & 0.623 & 0.062 & Valid \\
\hline YP8 & 0.776 & 0.062 & Valid \\
\hline YP9 & 0.795 & 0.062 & Valid \\
\hline YP10 & 0.805 & 0.062 & Valid \\
\hline YP11 & 0.599 & 0.062 & Valid \\
\hline YP12 & 0.757 & 0.062 & Valid \\
\hline YP13 & 0.762 & 0.062 & Valid \\
\hline YP14 & 0.742 & 0.062 & Valid \\
\hline YP15 & 0.726 & 0.062 & Valid \\
\hline
\end{tabular}

Sumber : Data diolah IBM SPSS 252021

Tabel 4 dapat menjelaskan bahwa hasil dari uji validitas keberhasilan MBKM di UTA 45 Jakarta menunjukan bahwa $r$ hitung $\geq \mathrm{r}$ tabel dengan nilai 0.062 . Hal ini dapat dijelaskan bahwa semua pernyataan-pernyataan yang diberikan dalam bentuk 
kuisioner kepada seluruh mahasiswa UTA 45 Jakarta dapat dikatakan valid. Uji validitas yang dilakukan pada mahasiswa UTA 45 Jakarta ini bertujuan untuk mengetahui layak atau tidaknya kuisioner yang dibuat oleh peneliti, sehingga dapat dilakukan ke tahap selanjutnya. Pada kesempatan ini peneliti untuk dapat mengetahui bagaimana hasil dari penyebaran kuisioner dapat dikatakan valid dengan cara membandingkan $r$ hitung dengan $r$ tabel. Pengujian validitas dan reabilitas ini menggunakan software IBM SPSS Statistics 25. Hasil dari uji kelayakan data dapat dikatakan bahwa jika $r$ hitung $\geq \mathrm{r}$ tabel, maka pernyatan dikatakan valid, kemudian jika $r$ hitung $\leq \mathrm{r}$ tabel, maka pernyataan dikatakan tidak valid.

\section{Uji Realibilitas}

Uji reabilitas wajib dilakukan untuk mendapatkan instrumen yang baik dengan cara uji Cronbach's Alpha. Hasil uji realibilitas ditampilkan pada tabel 5 .

Tabel 5. Uji Reabilitas Sosialisasi Kebijakan MBKM dan Keberhasilan Pelaksanaan MBKM di UTA '45 Jakarta

\begin{tabular}{|c|c|c|}
\hline Variabel & $\begin{array}{c}\text { Cronbach's } \\
\text { Alpha }\end{array}$ & $\begin{array}{c}\text { Cronbach's Alpha Based on } \\
\text { Standardized Items }\end{array}$ \\
\hline $\begin{array}{c}\text { Uji Reabilitas } \\
\text { Kebijakan } \\
\text { MBKM }\end{array}$ & 0.951 & 0.953 \\
\hline $\begin{array}{c}\text { Uji Reabilitas } \\
\text { Keberhasilan } \\
\text { MBKM }\end{array}$ & 0.943 & 0.944 \\
\hline
\end{tabular}

Sumber: data diolah IBM SPSS Ststisctic 25 


\section{Hipotesis}

Tabel 6. Hasil Uji Koefisien Determinasi ( $R$ square)

\begin{tabular}{|r|l|l|l|l|} 
Model & $\mathrm{R}$ & $\begin{array}{l}\mathrm{R} \\
\text { Square }\end{array}$ & $\begin{array}{l}\text { Adjusted } \\
\mathrm{R} \\
\text { Square }\end{array}$ & $\begin{array}{l}\text { Std. Error of the } \\
\text { Estimate }\end{array}$ \\
\hline 1 & $.909^{\mathrm{a}}$ & 0.827 & 0.827 & 3.06874 \\
\hline
\end{tabular}

Predictors: (Constant), $\mathrm{X}=$ Implementasi Program

MBKM

Tabel 6 menjelaskan besarnya nilai korelasi atau hubungan (R) yaitu sebesar 0.909 dan dijelaskan besarnya persentase bahwa Kebijakan MBKM yang berada di UTA 45 Jakarta yang disebut koefisien determinasi. Koefisien determinasi (R2) 82.7 yang mengandung pengertian bahwa Kebijakan MBKM dengan nilai $82.7 \%$. sedangkan sisanya dipengaruhi oleh variabel lain.

\section{E. Uji F}

Pengujian ini digunakan untuk dapat menguji banagimana pengaruh dari variabel kebijakan MBKM (bebas) terhadap variabel keberhasilan MBKM (terikat) pada UTA 45 Jakarta.

Tabel 7. Analisis Regresi Linier Sederhana

\begin{tabular}{|c|l|l|l|c|c|c|}
\hline \multicolumn{2}{|c|}{ Model } & $\begin{array}{c}\text { Sum of } \\
\text { Squares }\end{array}$ & \multicolumn{1}{c|}{ df } & $\begin{array}{c}\text { Mean } \\
\text { Square }\end{array}$ & F & Sig. \\
\hline \multirow{2}{*}{1} & Regression & 45476.497 & 1 & 45476.497 & 4829.095 & $.000^{\mathrm{b}}$ \\
\cline { 2 - 7 } & Residual & 9511.361 & 1010 & 9.417 & & \\
\cline { 2 - 7 } & Total & 54987.858 & 1011 & & & \\
\hline
\end{tabular}

a. Dependent Variable: Y=UTA 45 Jakarta

b. Predictors: (Constant), $\mathrm{X}=\mathrm{Implementasi}$ Program MBKM 
Hasil pada tabel 7 menunjukan bahwa hasil pengolahan data yang dapat dijelaskan bahwa nilai sign $0.000<0.05$ yang artinya bahwa H0 ditolak. Dengan kata lain, implementasi MBKM yang diterapkan pada kampus UTA 45 Jakarta dapat diimplementasikan dengan baik.

\section{F. Uji t}

Uji t digunakan untuk dapat menguji bagaimana pengaruh sosialisasi kebijakan MBKM (bebas) terhadap variabel keberhasilan pelaksanaan MBKM (terikat) di UTA '45 Jakarta.

Tabel 8. Penghitungan Uji t

\begin{tabular}{|c|c|c|c|c|c|c|}
\hline \multicolumn{7}{|c|}{ Coefficients $^{\mathbf{a}}$} \\
\hline \multirow{2}{*}{\multicolumn{2}{|c|}{ Model }} & \multicolumn{2}{|c|}{$\begin{array}{l}\text { Unstandardized } \\
\text { Coefficients }\end{array}$} & \multirow{2}{*}{$\begin{array}{l}\text { Standardized } \\
\text { Coefficients } \\
\text { Beta }\end{array}$} & \multirow{2}{*}{$\mathrm{T}$} & \multirow{2}{*}{ Sig. } \\
\hline & & B & $\begin{array}{l}\text { Std. } \\
\text { Error }\end{array}$ & & & \\
\hline & (Constant) & 2.655 & 0.852 & & 3.117 & 0.002 \\
\hline 1 & $\begin{array}{l}X=\text { Implementasi } \\
\text { Program } \\
\text { MBKM }\end{array}$ & 0.715 & 0.01 & 0.909 & 69.492 & 0 \\
\hline
\end{tabular}

a. Dependent Variable: Y=UTA 45 Jakarta

Diketahui bahwa nilai t hitung sebesar $69.492>1.962$. sehingga dapat disimpulkan bahwa variabel kebijakan MBKM (X) berpengaruh terhadap variabel keberhasilan MBKM (Y). Hasil pada tabel diatas menunjukan bahwa $\mathrm{t}$ hitung $69.492>\mathrm{t}$ tabel 1.962. Dengan demikian dapat disimpulkan bahwa sosialisasi kebijakan MBKM berpengaruh terhadap keberhasilan pelaksanaan MBKM di UTA '45 Jakarta. 
Hasil pengujian hipotesis pada uji t menunjukan bahwa sosialisasi kebijakan MBKM yang dilakukan oelh UTA '45 Jakarta berpengaruh signifikan terhadap keberhasilan pelaksanaan MBKM di UTA '45 Jakarta, hal ini dapat dilihat dari nilai sign sebesar $0.002 \leq 0.05$. Hasil tersebut juga didukung dengan nilai $\mathrm{t}$ hitung $69.492 \geq \mathrm{t}$ tabel 1.962. Dengan demikian, hipotesis H0 ditolak dan $\mathrm{H} 1$ diterima. Hal ini berarti sosialisasi kebijakan MBKM yang dilaksanakan oelh UTa '45 Jakarta dapat mempengaruhi keberhasilan implementasi progam MBKM di UTA 45 Jakarta.

Uji F pada pengolahan data penelitian ini menghasilkan $\mathrm{F}$ hitung sebesar 4.829 dengan nilai signifikansi sebesar $0.000 \leq$ 0.05, yang artinya sosialisasi kebijakan program MBKM di UTA '45 Jakarta mempengaruhi keberhasilan implementasi program MBKM di UTA 45 Jakarta.

Hasil dari pengolahan data koefisien determinasi ( $R$ variabel pada penelitian dpaat dilihat pada $\mathrm{R}$ square). Pada hasil pengolahan ini R square didapat sebesar $90.9 \%$ atau 0.909 yang artinya keberhasilan MBKM dapat dijelaskan oleh variabel kebijakan MBKM sebesar 9.1\% atau 0.91, sedangkan sisanya dijelaskan oleh faktor lain. Kebijakan MBKM mempunyai pengaruh yang kuat terhadap keberhasilan MBKM karena hasil yang didapat sangat besar. 
Dengan demikian, semua indikator yang diuji dalam penelitian ini menunjukkan bahwa sosialisasi kebijkan MBKM berpengaruh signifikan terhadap keberhasilan implementasi MBKM di UTA '45 Jakarta. Dari hasil pengolahan data tersebut, nilai tertinggi diperoleh pada pertanyaan 21 "Kegiatan program MBKM sangat penting untuk persiapan menghadapi masa pasca kampus", sedangkan nilai terendah diperoleh pada pertanyaan 27 "Saya selalu memberikan masukan maupun saran kepada Kementerian Pendidikan, Budaya, Riset, dan Teknologi R.I terkait upaya untuk kelancaran implementasi kebijakan merdeka belajarkampus merdeka”.

\section{KESIMPULAN DAN SARAN}

Sosialisasi yang dilakukan UTA '45 Jakarta berpengaruh signifikan terhadap keberhasilan implementasi program-program MBKM di UTA '45 Jakarta. Dari hasil penelitian ini, kami merekomendasikan UTA '45 Jakarta untuk menyediakan ruang bagi mahasiswa untuk dapat memberikan saran tentang pelaksanaan MBKM di UTA '45 Jakarta, dan saran-saran tersebut dapat diakses oleh pimpinan serta tim koordinator MBKM UTA '45 Jakarta. 


\section{UCAPAN TERIMA KASIH}

Pelaksanaan kegiatan dan publikasi artikel penelitian ini didukung oleh Kemendikbudristek R.I melalui Bantuan Pendanaan Program Penelitian Kebijakan Merdeka Belajar Kampus Merdeka dan Pengabdian Masyarakat Berbasis Hasil Penelitian dan Purwarupa PTS Ditjen Diktiristek Tahun Anggaran 2021.

\section{DAFTAR PUSTAKA}

Agustino, L. 2016. Dasar-Dasar Kebijakan Publik. Bandung: Alfabeta.

Baharuddin, M. R. 2021. Adaptasi Kurikulum Merdeka Belajar Kampus Merdeka (Fokus: Model MBKM Program Studi). Jurnal Studi Guru dan Pembelajaran, 4(1), 195-205. Diambil dari https://www.e-journal.my.id/jsgp/article/view/591

Direktorat Jenderal Pendidikan Tinggi. 2020. Buku Panduan Merdeka Belajar-Kampus Merdeka. Jakarta: Direktorat Jenderal Pendidikan Tinggi Kemdikbud R.I.

Fuadi, T. M., \& Aswita, D. 2021. Merdeka Belajar Kampus Merdeka (MBKM): Bagaimana Penerapan dan Kedala yang Dihadapi oleh Perguruan Tinggi Swasta di Aceh. Jurnal Dedikasi Pendidikan, 5(2), 603-614. Diambil dari http://jurnal.abulyatama.ac.id/index.php/dedikasi

Puspitasari, R., \& Nugroho, R. 2021. Implementasi Kebijakan Merdeka Belajar, Kampus Merdeka FISIP UPN Veteran Jawa Timur. Dinamika Governance: Jurnal Ilmu Administrasi 
Negara, 11(2), 276-292.

Rustan, A. S., \& Hakki, N. 2017. Pengantar Ilmu Komunikasi. Diambil dari https://books.google.co.id/books?hl=id\&lr=\&id=Ezk2DwA AQBAJ\&oi=fnd\&pg=PR6\&dq=komunikasi\&ots=bR3bKxqjh\&sig=XZzETnOn7fNtV2mRWtKimx7yP0\&redir_esc $=\mathrm{y} \# \mathrm{v}=$ onepage $\& \mathrm{q}=$ komunikasi $\& \mathrm{f}=$ false\%0Ahttps://books.google.co.id/books?id=Ezk2Dw AAQBAJ\&pg=PA28\&dq=Pengertian+berko

Syarif, A., Unde, A. A., \& Asrul, L. 2014. Pentingnya Komunikasi dan Informasi pada Implementasi Kebijakan Penyelenggaraan Penanggulangan Bencana di Kota Makassar. Jurnal Komunikasi KAREBA, 3(3), 142-152. Diambil dari https://journal.unhas.ac.id/index.php/kareba/article/view/583

Thomas, A. S. 2018. Penggunaan Saluran Komunikasi dalam Menjaga Sikap Hidup Toleransi Beragama di Desa Kema Satu Kabupaten Minahasa Utara. Al Qalam, 24(2), 344-358. https://doi.org/10.31969/alq.v24i2.537 